\title{
Enhancement of biogas production from rice husk using mechanical pretreatment (grinding) in Liquid Anaerobic Digestion (L-AD)
}

\author{
Syafrudin $^{1 *}$, Winardi Dwi Nugraha ${ }^{1}$, Soraya Annisa Putri ${ }^{1}$, Hashfi Hawali Abdul Matin ${ }^{2}$, \\ and Budiyono ${ }^{3}$ \\ ${ }^{1}$ Environmental Engineering Department, Faculty of Engineering, Diponegoro University, Semarang, 50275, \\ Indonesia \\ ${ }^{2}$ Environmental Science, Faculty of Mathematic and Natural Science, Sebelas Maret University, Surakarta, \\ Indonesia \\ ${ }^{3}$ Chemical Engineering Department, Faculty of Engineering, Diponegoro University, Semarang, 50275, Indonesia
}

\begin{abstract}
Biogas technology is an alternative solution to the energy crisis issue in Indonesia. This study focuses on determining the optimum value of grind size variations in biogas production using the Liquid Anaerobic Digestion (L-AD) from rice husk waste. It is consists of the preparation stage, total solids calculation, the operation phase, and results analysis. The rice husk is collected from Rowosari village, and it has been pre-treated by $6 \% \mathrm{NaOH}$ of chemical pre-treatment. The physical treatment uses numerous grind sizes, including un-grinded rice husk as control, and the 10 mesh, 18 mesh, 35 mesh, 60 mesh of rice husk as an observed variable. All variables are duplicate into 12 reactors, and the biogas production is observed by collecting gas volume in each reactor for 60 days. The calculated biogas is expressed by $\mathrm{ml} / \mathrm{grTS}$. The result shows that the grind size of 10 mesh, 18 mesh, 35 mesh, and 60 mesh rice husk produces a total biogas rate of $54.95,44.86,58.13$, and $72.14 \mathrm{ml} / \mathrm{grTS}$ respectively. The rice husk control produces $9.67 \mathrm{ml} / \mathrm{gr}$ TS as the lowest rate of biogas production compared to the others, while the 60 mesh rice husk becomes the highest biogas production rate.
\end{abstract}

\section{Introduction}

Current world energy consumption still depends on fossil energy sources, which predicts to run out very soon. This issue also occurs in Indonesia, which is very dependent on fossil fuels. Reducing dependence on un-renewable energy, especially oil and gas, is one of the efforts to improve national long-term energy security by substitutes for new and renewable energy sources [1]. Biogas energy utilization is an alternative solution of renewable energy. Biogas is an anaerobic end product of digestion/degradation in an oxygen-free environment produced by the activity of methanogenic bacteria.

The potential for biogas development in Indonesia is very significant, especially in rural areas where most people work in the field of animal husbandry and agriculture. The rice

* Corresponding author: udin_syaf@yahoo.com 
farming (agriculture) sector produces a familiar waste in the form of rice husk, which has a great potential to be used as raw material for producing biogas. The rice husk contains $9 \%$ of water content, and it consists of hollow tissue, fermentable material, and has high energy. Therefore, it becomes very potential in producing gas [2].

In order to obtain optimal biogas production, it is necessary to pay attention to several decomposition factors consisting of temperature, $\mathrm{pH}, \mathrm{F} / \mathrm{M}$ ratio (Food to Microorganisms), $\mathrm{C} / \mathrm{N}$ ratio, alkalinity, and total solid content. The decomposition of organic material containing cellulose, hemicellulose, and lignin compounds takes place very slowly, so it needs a pre-treatment process [3]. The pre-treatment process can be done physically (milling, heating with steam and radiation), chemically (acid hydrolysis and base hydrolysis), and biologically (enzymatically) using microorganisms that hydrolyse lignocellulose [4].

Physical pre-treatment by grinding, heating with steam, and radiation can increase the biogas production. Grinding provide a higher possibility for increasing the decomposition rate of the substrate because it allows the expansion of the substrate surface to be decomposed by microorganisms. Reducing particle size increases the rate of enzymatic degradation, reduces the viscosity in the digester (mixing easier), and reduce the problem of floating layers [5].

Related to this study, previous research have conducted a study on grinding biomass as pre-treatment for bio gasification with dry straw material. The variations size of milling dry straw used in their study was $0.5 \mathrm{~mm}, 20 \mathrm{~mm}, 30 \mathrm{~mm}$ [6]. The biogas production was observed, and it was known that almost $10 \%$ of biogas was produced from the $0.5 \mathrm{~mm}$ rice straw higher than 20 to $30 \mathrm{~mm}$ rice straw. These results show the tendency of cutting impacts on biogas yield. It also reported the negative correlation between biogas yield, particle size, and lignin content significantly for most hay samples analysed [6].

As the results of previous research, it is necessary to conduct a study related to the optimization of biogas production through physical pre-treatment (grinding) of rice husks. The aim of this study is to determine the impact of physical treatment (grinding) on various sizes of rice husk as an effort to enhance biogas yield. This study calculates total solids in rice husk, varies the size of rice husk as a substrate, then observes quantitative and qualitatively biogas yields for 60 days of research. Factors that can affect biogas yield, such as $\mathrm{pH}$, temperature, and $\mathrm{C} / \mathrm{N}$ ratio will be investigated.

\section{Methodology}

This research was carried out in 2019-2020 at the Environmental Laboratory, Department of Environmental Engineering, Diponegoro University, Indonesia. It was conducted with a duplicated sample to obtain the reliability and validity of the data taken from each variable accurately. This study uses size variations of rice husk with 10 mesh $(2 \mathrm{~mm}), 18$ mesh (1 $\mathrm{mm}), 35$ mesh $(0.5 \mathrm{~mm})$, and 60 mesh $(0.25 \mathrm{~mm})$, which has been sieved using a shiver. Determination of size variations approaching 35 mesh was chosen to find out whether there is an optimal value of the size that has been studied in previous studies [6].

This research begins with collecting rice husks from Rowosari, Central Java, then measures its TS (Total Solid) levels using the standard APHA method. Rice husks were pre-treated by $6 \% \mathrm{NaOH}$ for 24 hours in order to remove the lignin. It is necessary to identify a leaking gas in the digester before start the operation to ensure the anaerobic conditions. The leak test is carried out by coating the soap foam in the gaps of the digester, which could cause any leakage. For the experimental setup, the cut rice husk, enzymes, $\mathrm{C} / \mathrm{N}$ ratio, and total solid content were adjusted according to the experimental design. Biogas yield was carried out in a $600 \mathrm{ml}$ biodigester, equipped with a tight rubber plug and fitted 
by a valve on the top as show in Figure 1. During the operation process, biogas volume is measured every two days by the liquid displacement method.

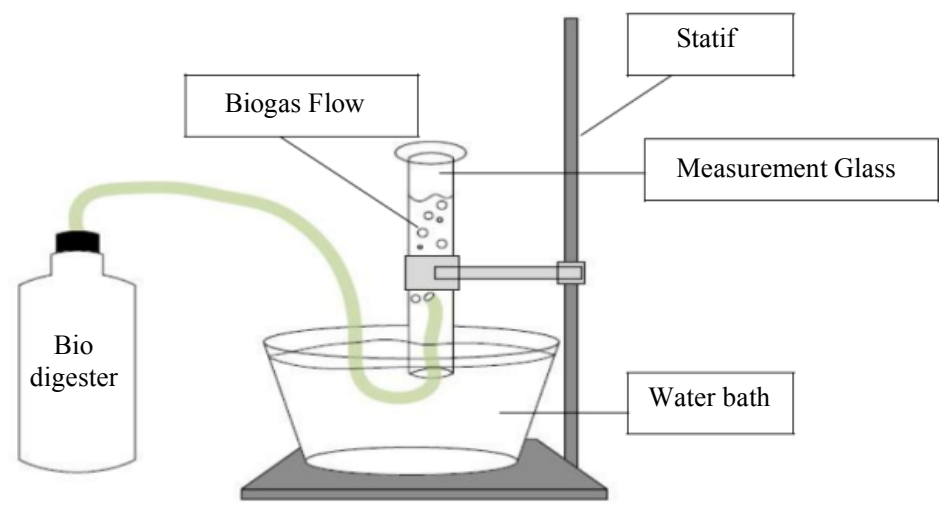

Fig 1. Schematic diagram of bioreactor in laboratory scale

In addition to measuring biogas volume, $\mathrm{pH}$ and temperature observation are needed using universal litmus paper and a thermometer where it settled permanently in the reactor. At this stage, the rice husk structure was also analysed using the Scanning Electron Microscope (SEM) to determine the microstructure of rice husk after the biogas formation process.

Biogas volume data were analysed in the form of biogas volume graphs relationship with time using Polymath 6.1 and Microsoft Office Excel software. The experimental data were fitted to the standard biogas production model of Gompertz, a mathematical model for time series observation. The effect of total solid concentration on biogas production from rice husk by liquid anaerobic digestion method was determined by non-linear regression of Eq. 1 to experimental data. The predicted data were presented in $2 \mathrm{D}$ graphs, and the significant evaluation of biogas in different experimental runs was statistically defined at $\mathrm{P}<0.05$.

$$
P=A \cdot \exp \left\{-\exp \left[\frac{U e}{A}(\lambda-1)+1\right]\right\}
$$

Where:

$$
\begin{array}{ll}
\mathrm{A} & =\text { Growth at lower asymptote } \\
\mathrm{U} & =\text { Maximum specific growth rate } \\
\lambda & =\text { Lag time (days) } \\
\mathrm{e} & =\text { Exponent }(2.718281828), \text { and } \\
\mathrm{t} & =\text { Sampling time (days) }
\end{array}
$$

\section{Results and Discussions}

\subsection{Preliminary Treatment and Liquid Anaerobic Digestion}

The Total Solid (TS) content of the rice husk has been tested from the rice mill location in Rowosari, Central Java. TS test was carried out using the APHA standard resulting 93,4\% of total solid contents. This condition is used to determine the composition of the material in the reactor in order to obtain the condition of Liquid Anaerobic Digestion. 
The pre-treatment carried out in this research is chemical pre-treatment and physical pre-treatment. This effort were completed in order to accelerate the process of lignocellulose degradation and to increase biogas yield [7]. Chemical pre-treatment is done by soaking rice husk in a solution of $\mathrm{NaOH}$ base. The ideal condition is 1 kilogram of rice husk soaked in 30 litres of water [8]. In this study, $1.5 \mathrm{~kg}$ of rice husk was soaked with a concentration of $6 \% \mathrm{NaOH}$ in 45 litres of water for 24 hours. The $6 \% \mathrm{NaOH}$ concentration was chosen because it produced the highest biogas yield compared to other $\mathrm{NaOH}$ concentrations [9].

In addition to chemical pre-treatment, physical pre-treatment was carried out in the form of rice husk grinding and sieving using sieves with sizes 10 mesh $(2 \mathrm{~mm}), 18$ mesh $(1 \mathrm{~mm})$, 35 mesh $(0.5 \mathrm{~mm})$, and 60 mesh $(0.25 \mathrm{~mm})$. The selection of sieving size is based on previous research, which states that the most optimal size of rice straw counting is 35 mesh [6]. The addition of variation sizes approaching the 35 mesh cutting rice straw is chosen to find out whether there is an optimal value of the other sizes above or below 35 mesh. In anaerobic biogas production, mechanical treatments such as grinding are performed to open cellular structures, increase the specific surface area of biomass, and provide greater possibilities for increasing the rate of substrate decomposition [6].

This study uses the L-AD or Liquid Anaerobic Digestion method with a Total Solid (TS) condition of $10 \%$. It is known that the total solid content of Liquid anaerobic digestion (L-AD) is used at $0.5-15 \%$ [10]. The L-AD condition was used because the digester's microorganisms were mixed entirely and suspended with the substrate in the digester. It was also necessary to determine the results of biogas production from rice husk with variations size of grinding using the wet conditions [11].

\subsection{Effect of Grinding Size Variations}

Based on Figure 2, it is known that the highest biogas yield is found in the 60 mesh reactor, which producing a biogas yield of $143.5 \mathrm{ml}$ on the 40th day. Then on the 60th day, the four reactors still produce biogas. However, the smallest biogas production is in the 18 mesh reactor, which produces a total biogas yield of $960.5 \mathrm{ml}$.

During 60 days of observation, there were fluctuate biogas yields on the 30th day. The condition of the decrease in the total growth of anaerobic bacteria was understated that environmental changes could result in changes in the morphological and physiological characteristics of microbes and affect microbes growth in new media [12]. The decline occurred because methanogenic bacteria are still in the phase of adaptation to the environment or new media [12]. On day 0 up to 28th day, it is estimated that the existence of the biogas process is in the log phase, where gas production begins to emerge. There is a high biogas yield on the 8th day which is estimated to be in the form of $\mathrm{CO} 2$ gas which is formed because initially there is oxygen in the reactor so that anaerobic microorganisms are still adapting to the reactor conditions. Start on the 30th day, there was an increase in biogas and continued to increase until the 40th day. This phenomenon has occurred because the bacterial growth phase has entered into a logarithmic or exponential phase where cells divide at a constant rate with mass doubling so that metabolic activity is constant and the total growth state of anaerobic bacteria is balanced. Then on the 42nd day to the 60th day, there is a sub-peak phase where biogas production has begun to decline, but there is still biogas production. In this phase, there is a decrease in the number of easily digestible substrates, such as cellulose and hemicellulose, resulting in decreased biogas production. 


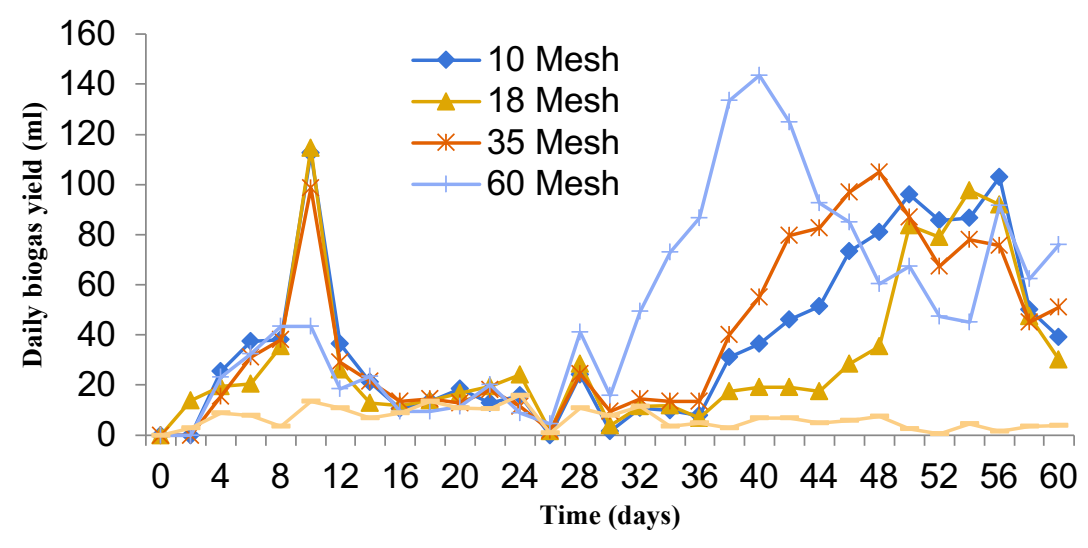

Fig. 2. Daily biogas yield presented in $\mathrm{ml}$

In this study, fluctuate trends are made possible by cellulose degradation at different speeds. The high production is affected by the high speed of biogas production, which was triggered by rapid cellulose degradation until cellulose degradation was rather slow.

The difference in biogas production volume trends also appears from the use of L-AD and SS-AD conditions. In the study of variations in grinding sizes, it is estimated that the use of the L-AD method has a high biogas volume trend. The dilution process (with stirring) can shift the time of biogas production to a few days earlier than if the reactor was not diluted [13]. Besides, the dilution has twice the ability to increase biogas production more than reactors with drier substrate conditions. Also, the dilution or L-AD method would accelerate the biogas production [14].

Based on the TS variations in the Figure 3, the 60 mesh reactor with the smallest rice husk size produced the highest biogas yield of $48.38 \mathrm{ml} / \mathrm{grTS}$ with a TS percentage of 93.4\% regarding the mechanical pre-treatment of wheat straw with a reduction in particle size from 2.0 to $0.2 \mathrm{~cm}$, which will increase methane yield up to $26 \%$ [15]. Most mechanical pre-treatment with reduced particle size will trigger an increase in the rate of degradation and reduce technical processing problems resulting in higher biogas. The pretreatment with grinding causes the breaking of the lignin seal, which disrupts the cellulose crystal structure. Lignin cells that have been broken would cause greater surface contact with hydrolytic enzymes. This phenomenon can more quickly convert carbohydrate polymers into sugar monomers so that they help speed up the fermentation process.

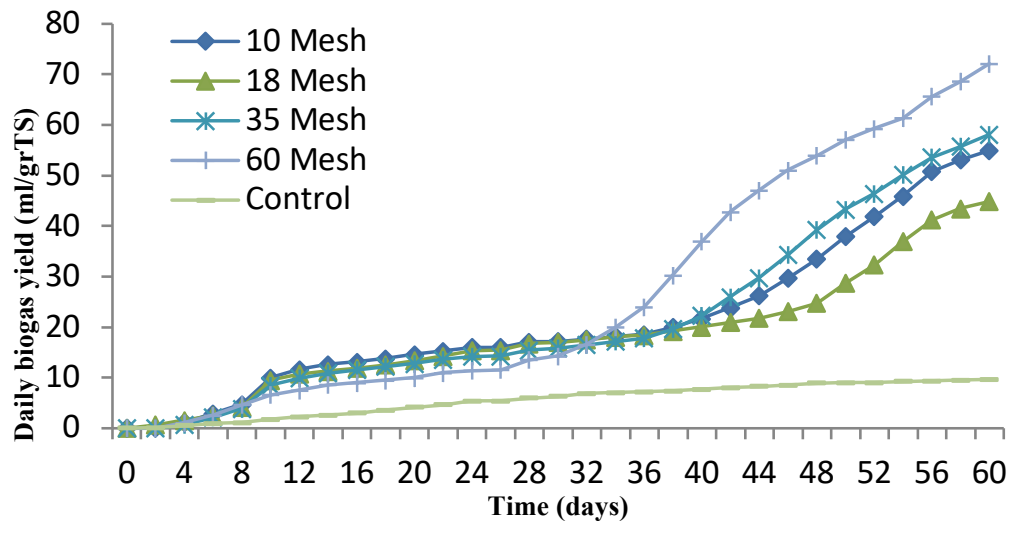

Fig. 3. Cumulative daily biogas yield presented in $\mathrm{ml} / \mathrm{grTS}$ 
According to this study, size variations of rice husk have a significant effect on biogas production, the smaller size of biomass waste treated, the higher biogas yields produced. In this study, the highest biogas yields produced in a 60 mesh $(0.25 \mathrm{~mm})$ rice husk. It is in line with previous research that the smaller value of particle size will produce a higher biogas yield [6]. Another research supports the concept that physical pre-treatment like grinding and reducing particle size can reduce the volume of digester needed and increase biogas production significantly [16].

\subsection{Biogas Production Rate}

The existence of variations in grinding size has an influence on the production kinetics constant. Based on the results of kinetic constants that have been analysed using Polymath 6.1 , there is a real difference in the production of daily biogas (A) rice husks treated by a physical pre-treatment with rice husks that are not treated by physical pre-treatment (control). In addition, the rates of biogas production (U) in control lower than rice husks that have been given pre-treatment.

Table 1 and Figure 4 show that the cutting size of 60 mesh rice husk significantly affected the kinetics constants of biogas production. Mathematically, the size of 60 mesh gives the highest biogas production rate expressed as a constant, i.e., maximum biogas production $(\mathrm{A})$, biogas production rate constant $(\mathrm{U})$ and minimum time of biogas formation $(\lambda)$ of $102.0000 \mathrm{ml} / \mathrm{gr}$ TS; $1.24154 \mathrm{ml} / \mathrm{gr}$ TSday; and 9.403631 days.

Table 1. Kinetic constant on the effect of variation in grinding size

\begin{tabular}{|c|c|c|c|c|c|}
\hline Konstanta & $\mathbf{1 0}$ mesh & $\mathbf{1 8}$ mesh & 35 mesh & 60 mesh & Kontrol \\
\hline $\mathbf{A}, \mathbf{m l} /$ grTS & 101.9995 & 101.9998 & 101.9995 & 102.0000 & 10.04575 \\
\hline $\mathbf{U}, \mathbf{m l} /$ (grTS.hari) & 0.935061 & 0.787901 & 1.069214 & 1.24154 & 0.2510094 \\
\hline $\boldsymbol{\lambda}$, hari & 9.952523 & 10.39021 & 12.37079 & 9.403631 & 3.983004 \\
\hline
\end{tabular}

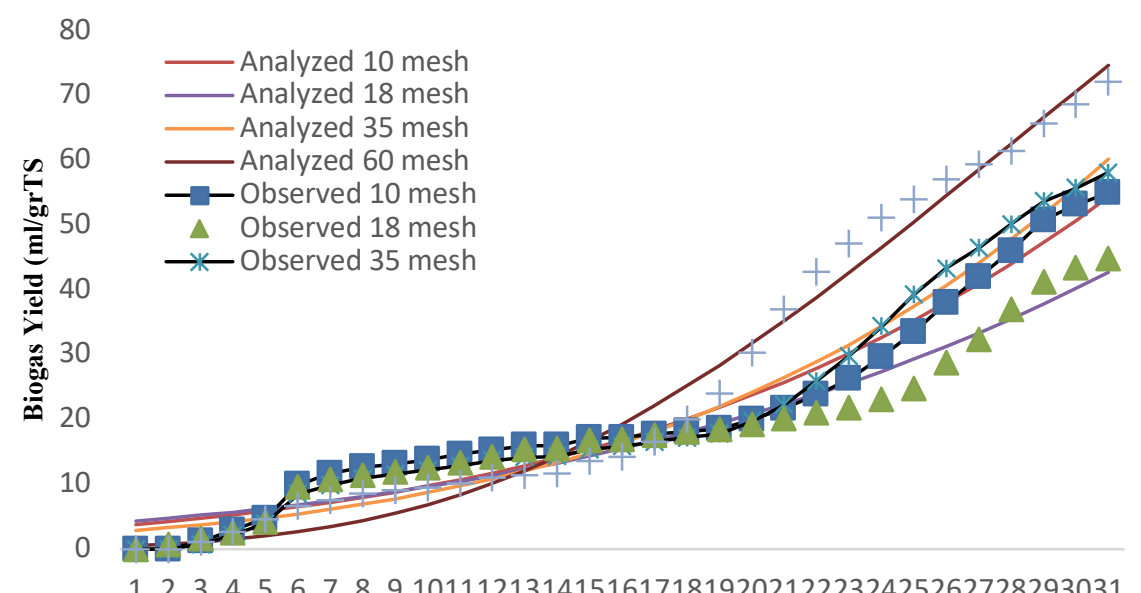

12345678910111213141516171819202122232425262728293031

Time (days)

Fig. 4. The correlation between experimental data and calculation results on the effects of grind size

The graph above shows a comparison of research data and Polymath software calculation data for 60 days. Based on Figure 4, the most significant biogas yield with the highest rate is found in 60 mesh rice husk, $72,139 \mathrm{ml} / \mathrm{gr}$ TS and biogas formed on the first day. On this measure, there is a daily production constant (A) of $94.8274 \mathrm{ml} / \mathrm{gr} \mathrm{TS}$ and 
biogas (U) production rate constant of $1.227925 \mathrm{ml} / \mathrm{gr}$ TS. The data generated based on research is not much different from the actual calculations, thus minimizing data deviations that are too far away. It can be seen in the R2 value obtained in each calculation based on its concentration measurement, where the R2 value between 0.75 to 0.99 shows a solid correlation between the two variables compared.

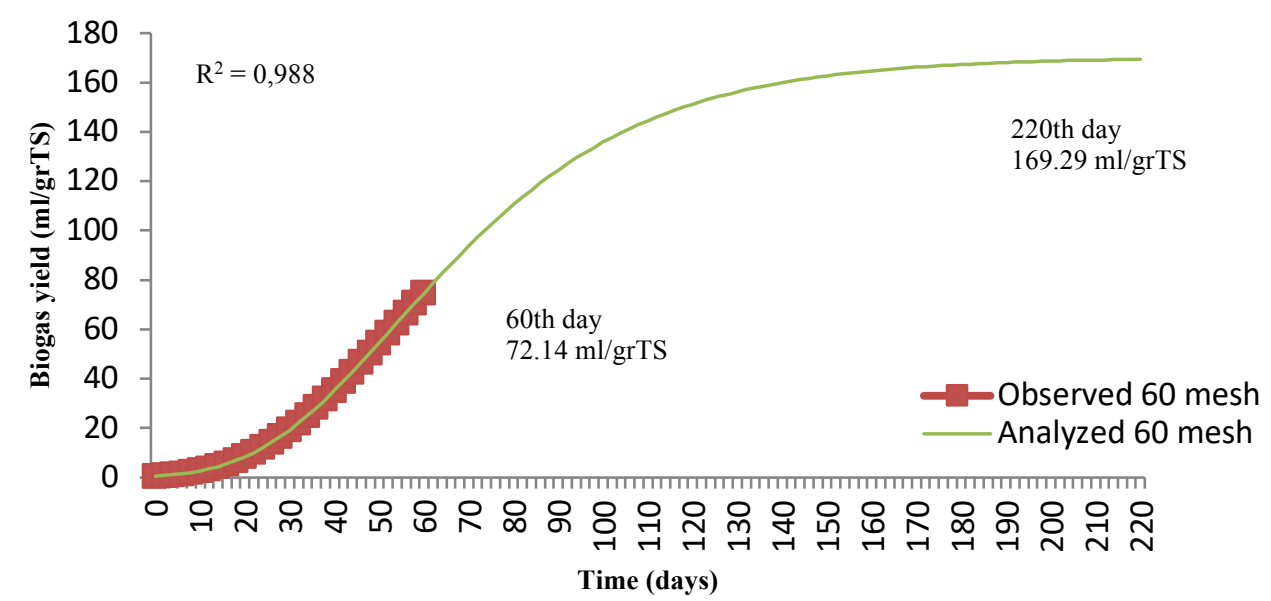

Fig. 5. Calculation Results using Polymath 6.1 on Variation in Grinding Size

After knowing the maximum biogas yield that can be produced, then Figure 5 identified on what day the biogas production will stop. On the 60th day, the biogas yield was 120 $\mathrm{ml} / \mathrm{gr}$ TS. Until the 220th day, the biogas continued to produce a maximum of $169.39 \mathrm{ml} / \mathrm{gr}$ TS. However, after the 220th day, there is no significant increase in biogas production. This phenomenon shows that biogas production from 60 mesh rice husk has tended to be stable and is predicted to stop on 220 days with a biogas yield of $169.29 \mathrm{ml} /$ grTS. This invention can be used to design bio digesters in L-AD conditions from rice husk waste with 60 mesh grinding treatment continuously with a residence time of 220 days.

\subsection{Morphological Structure of Treated Rice Husk}

The results of the Scanning Electron Microscope (SEM) test were used to determine the morphological structure of rice husks both before and after treatment in the formation of biogas. Based on the SEM test, the results of the image obtained indicate that there is an influence of decomposition during biogas formation on the morphological structure of rice husk shown in Figure 6 and Figure 7.

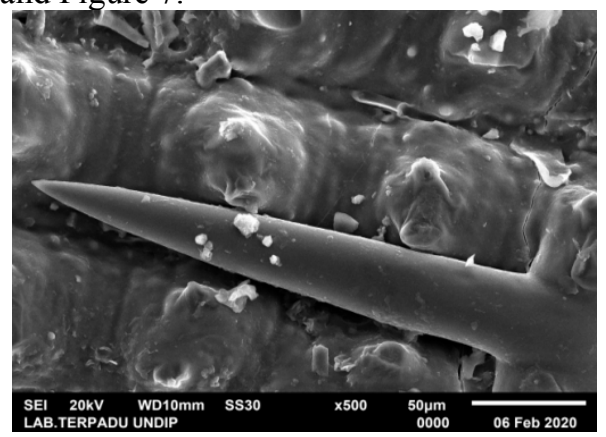

Fig. 1. SEM of rice husk before pre-treatment with 500x magnification 


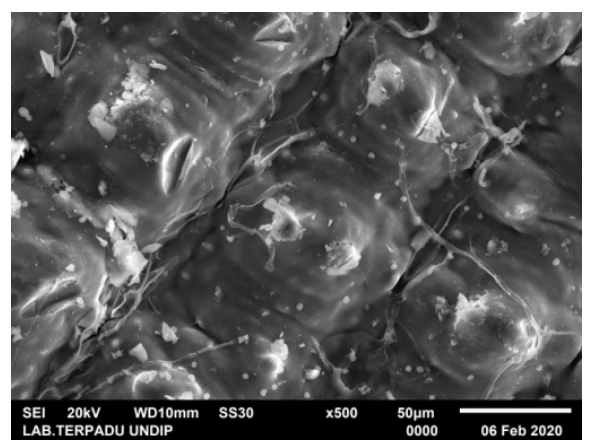

Fig. 7. SEM of rice husk after pre-treatment with 500x magnification

Rice husk, which has not been given any treatment and is still in its initial condition, shows a neat and orderly morphological structure. After being used as a substrate in biogas production, the rice husk's structure shows irregular morphology and looks torn. This phenomenon is occurred due to pre-treatment carried out to eliminate the structure of lignin in rice husks so that cellulose and hemicellulose surrounded by lignin can quickly be decomposed. The content of hemicellulose will support anaerobic microorganisms to degrade cellulose into biogas. The addition of $\mathrm{NaOH}$ during the pre-treatment process also causes damage to the biomass structure so that it can be easily converted into glucose compounds [17].

\section{Conclusions}

Grinding on rice husk with liquid method affects the production of biogas yield. Pretreatment of rice husk by grinding produces higher biogas yield compared to rice husk without grinding process. 60 mesh grinding size resulting in optimum biogas yield of $102,000 \mathrm{ml} /$ grTS for 60 days with a constant biogas production rate of $1.24154 \mathrm{ml} /$ grTSday. Also, 60 mesh grinding size resulting in the highest biogas production rate of $102,000 \mathrm{ml} / \mathrm{gr}$ TS starting to form on the first day. Daily production constant (A), biogas production rate constant $(\mathrm{U})$ and minimum time for biogas formation; $102,000 \mathrm{ml} / \mathrm{gr} \mathrm{TS}$; $1.24154 \mathrm{ml} / \mathrm{gr}$ TSday; and 9.403631 days respectively.

The application of this research is based on our findings to optimize rice husk as an alternative source of biogas production with the liquid anaerobic digestion method. Research related to the optimization of biogas production can also be applied to other agricultural wastes that have high cellulose content. This study found the optimal conditions for biogas production from rice husk waste affected by size, $\mathrm{C} / \mathrm{N}$ ratio, and $\mathrm{TS}$ factors resulting in high biogas productivity. Further study is needed to evaluate other possible variables, such as the mixture's $\mathrm{pH}$, temperature, and the characteristics of gas produced. Nevertheless, biogas optimization from rice husks can be obtained by producing biogas through a larger scale such as pilot-scale and industrial scale. 


\section{References}

[1] S. Shafiee and E. Topal, "When will fossil fuel reserves be diminished?," Energy Policy, vol. 37, no. 1, pp. 181-189 (2009)

[2] C. S. Prasad, K. N. Maiti, and R. Venugopal, "Effect of rice husk ash in whiteware compositions," Ceram. Int., vol. 27, no. 6, pp. 629-635 (2001)

[3] J. Taghinazhad, R. Abdi, and M. Adl, "Kinetic and Enhancement of Biogas Production For The Purpose of Renewable Fuel Generation by Co-digestion of Cow Manure and Corn Straw in A Pilot Scale CSTR System," International Journal of Renewable Energy Development, vol. 6, no. 1, pp. 37-44, (2017)

[4] J. Vadiveloo, B. Nurfariza, and J. G. Fadel, "Nutritional improvement of rice husks," Anim. Feed Sci. Technol., vol. 151, no. 3-4, pp. 299-305 (2009)

[5] L. Kratky and T. Jirout, "Biomass Size Reduction Machines for Enhancing Biogas Production," Chem. Eng. Technol., vol. 34, no. 3, pp. 391-399 (2011)

[6] A. Menind, A. Normak, and others, "Study on Grinding Biomass as Pre-treatment for Biogasification,” Int. Sci. Conf., p. 155 (2009)

[7] R. Chandra, H. Takeuchi, and T. Hasegawa, "Hydrothermal pretreatment of rice straw biomass: A potential and promising method for enhanced methane production," Appl. Energy, vol. 94, pp. 129-140 (2012)

[8] Syafrudin, W. Dwi Nugraha, H. Hawali Abdul Matin, and Budiyono, "The effect of enzymatic pretreatment and $\mathrm{c} / \mathrm{n}$ ratio to biogas production from rice husk waste during solid state anaerobic digestion (SS-AD)," MATEC Web Conf., vol. 101 (2017)

[9] Syafrudin, W. D. Nugraha, S. S. Agnesia, H. H. A. Matin, and Budiyono, "Enhancement of Biogas Production from Rice Husk by $\mathrm{NaOH}$ and Enzyme Pretreatment," E3S Web Conf., vol. 31, no. February 2017, pp. 2-7, 2018.

[10] J. Zhu, C. Wan, and Y. Li, "Enhanced solid-state anaerobic digestion of corn stover by alkaline pretreatment," Bioresour. Technol., vol. 101, no. 19, pp. 7523-7528 (2010)

[11] G. D. and V. Grilc, "Anaerobic Treatment and Biogas Production from Organic Waste," Manag. Org. Waste, vol. 2 (2012)

[12] J. Wahyudi, "The Determinants Factors of Biogas Technology Adoption in Cattle Farming: Evidences from Pati, Indonesia," International Journal of Renewable Energy Development, vol. 6, no. 3, pp. 235-240, (2017).

[13] A. Mshandete, L. Björnsson, A. K. Kivaisi, M. S. T. Rubindamayugi, and B. Mattiasson, "Effect of particle size on biogas yield from sisal fibre waste," Renew. Energy, vol. 31, no. 14, pp. 2385-2392 (2006)

[14] O. C. Okeh, C. O. Onwosi, and F. J. C. Odibo, "Biogas production from rice husks generated from various rice mills in Ebonyi State, Nigeria," Renew. Energy, vol. 62, pp. 204-208 (2014)

[15] D. Gallegos, H. Wedwitschka, L. Moeller, A. Zehnsdorf, and W. Stinner, "Effect of particle size reduction and ensiling fermentation on biogas formation and silage quality of wheat straw," Bioresour. Technol., vol. 245, no. July, pp. 216-224 (2017)

[16] C. Herrmann, M. Heiermann, C. Idler, and A. Prochnow, "Particle Size Reduction during Harvesting of Crop Feedstock for Biogas Production I: Effects on Ensiling Process and Methane Yields," Bioenergy Res., vol. 5, no. 4, pp. 926-936 (2012) 
[17] H. H. A. Matin and H. Hadiyanto, "Optimization of biogas production from rice husk waste by solid state anaerobic digestion (SSAD) using response surface methodology," J. Environ. Sci. Technol., vol. 11, no. 3, pp. 147-156 (2018) 